\title{
Die Jeverschen Pastorenbekenntnisse 1548 anlässlich des Augsburger Interim
}

Hrsg. v. Rolf Schäfer

Die Jeverschen Pastorenbekenntnisse 1548 anlässlich des Augsburger Interim Herausgegeben von
ROLF SCHÄFER

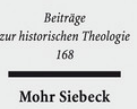

2012. XIII, 611 Seiten. BHTh 168

ISBN 978-3-16-152132-4

DOI 10.1628/978-3-16-152132-4

eBook PDF 159,00€

ISBN 978-3-16-151910-9

Leinen $159,00 €$
Die Herrschaft Jever geriet durch das Augsburger Interim 1548 unter großen Druck. Zur Bündelung der eigenen Kräfte wurden alle Pastoren beauftragt, ihren persönlichen Glauben und ihre Ablehnung des Interim schriftlich zu begründen. So entstand eine einzigartige Sammlung von 21 Pastorenbekenntnissen, die dank glücklicher Umstände erhalten blieb. Sie bietet ein flächendeckendes Bild, wie weit die Reformation fernab der Bildungszentren des Reichs in einem ländlichen Territorium durchgedrungen war. Die Verfasser haben zum Teil studiert, zum Teil aber nur die einfache Klerikerausbildung des Spätmittelalters durchlaufen. Die lateinischen und niederdeutschen Bekenntnistexte werden erstmals von Rolf Schäfer vollständig ediert und durch eine parallel angeordnete Übersetzung sowie durch eine historische Einleitung erschlossen.

Rolf Schäfer Geboren 1931; Theologiestudium in Tübingen, Göttingen und Zürich; 1967 Habilitation Tübingen; 1971-94 Oberkirchenrat in Oldenburg; seit 1994 im Ruhestand.

\section{Jetzt bestellen:}

https://mohrsiebeck.com/buch/die-jeverschen-pastorenbekenntnisse-1548-anlaesslich-des-augsburger-interim9783161521324?no_cache $=1$

order@mohrsiebeck.com

Telefon: +49 (0)7071-923-17

Telefax: $+49(0) 7071-51104$ 